\title{
A model to approach BIM adoption process and possible BIM implementation failures.
}

\author{
Elodie Hochscheid ${ }^{\mathrm{a}}$, Gilles Halin ${ }^{\mathrm{b}}$ \\ a PhD candidate, MAP-CRAI, Ecole Nationale Supérieure d'Architecture de Nancy, France. \\ ${ }_{b}$ Professor, MAP-CRAI, Ecole Nationale Supérieure d'Architecture de Nancy, France.
}

\begin{abstract}
Adoption of Building Information Modelling (BIM) has increased significantly over the last few years. In France, the level of BIM adoption is measured as quite low compared to other countries. Many guides, protocols and mandates have been produced by governmental bodies and industry associations around the world to facilitate BIM adoption but it mainly focus on technical requirements or describe good practices. This paper is part of a research project that aims to facilitate BIM implementation for design firms by providing an implementation guide or method. This method would be organization-centered (based on the specificities of the company) with more organizational and managerial than technical considerations. Connecting BIM AdoptionImplementation literature with change management (a domain that provides models and strategies to analyze and conduct change) carries an interesting research potential that is insufficiently investigated. The objective of this article is to have a relatively comprehensive view of the factors that can influence the success or failure of BIM adoption, especially at the implementation phase.
\end{abstract}

(C) 2018 The Authors. Published by Diamond Congress Ltd., Budapest University of Technology and Economics Peer-review under responsibility of the scientific committee of the Creative Construction Conference 2018.

Keywords: BIM; AEC; AECO; architecture firms; adoption; diffusion; implementation; implementation failure; adoption drivers; implementation drivers; adoption decision factors; adoption failure; implementation failure; change management; change; risk management; literature review; conceptual model; guide; method.

\section{Introduction}

Building Information Model/Modeling/Management (BIM) is a technology (including technique and processes) based on exploitation/exchange of digital mock-up between construction project actors for buildings lifecycle management. It is considered as an emerging technological shift [1] within the Architecture, Engineering and Construction and Operation (AECO) industry.

Many guides, protocols and mandates have been produced by governmental bodies and industry associations to facilitate BIM adoption [2] but it mainly focus on technical requirements or describe good practices. Connecting BIM diffusion/adoption/implementation literature with change management (a domain that provides models and strategies to analyze and conduct change) carries an interesting research potential that is insufficiently investigated [3].

This paper is part of a research project that aims to facilitate BIM implementation for design firms by providing an implementation guide or method based on the specificities of the company, with more organizational and managerial than technical considerations. The first step is to study how this company works to identify organizational factors that are likely to affect implementation (cause implementation to fail or succeed). It comes down to identify risk factors (internal context, external context, culture, interactions, systems and people [4]) which may make BIM implementation more complex, and manage it (as in risk management field, for transition project [5]). 
The objective of this article is to have a relatively comprehensive view of the factors that can influence the success or failure of BIM adoption identified in the literature, especially at the implementation stage. First, we clarify definitions of diffusion, adoption and implementation (part 2). Then, we will identify the factors that have been identified in the literature as playing a role in the adoption and success or failure in implementation of an innovation (part 3). In the discussion (part 4) we will propose a model to approach BIM adoption process and possible BIM implementation failures based on the state of the art proposed in part 3. As a conclusion (part 5), we will present research perspectives based on this model.

\section{Diffusion, Adoption, Implementation.}

BIM is considered an innovation. The lexical field generally attributed to the spread of innovations is also attributed to BIM (diffusion, adoption and implementation). However, the definitions of these terms are not always explicit in BIM-specific literature, and are sometimes different:

- Diffusion is "a concept that represents the spreads of the system/process within a population of adopters" [6]. "The diffusion process is characterized by increases over time in both the number of firms using or owning a technology (inter-firm diffusion) and more intensive use of the technology by the firm (intra-firm diffusion)." [7].

- Implementation is "a set of activities undertaken to prepare for, deploy or improve specific deliverables and their related workflows" [6].

- Adoption is the most unclear term. It sometimes refers to a company's management decision to start integrating a technology; to the moment the technology is well mastered; or to a process that includes implementation.

Everett Rogers published in 1963 the first version of one of the most famous research on innovation: Diffusion of Innovations [8]. He describes the innovation-decision process in five stages (table 1). This model has been adapted, renamed, and became the model of the adoption process [9] (see table 1) and readapted more recently in BIM-specific literature [10] (table 1), where Decision (at stage 3) became Point of Adoption.

Table 1 : Different models in five stages that describe innovation-decision process / adoption process.

\begin{tabular}{llllll} 
Stage 1 & Stage 2 & Stage 3 & Stage 4 & Stage 5 & Ref. \\
\hline Knowledge & Persuasion & Decision & Implementation & Confirmation & {$[8]$} \\
\hline Awareness & Interest & Trial & Evaluation & Adoption & {$[9]$} \\
\hline Awareness & Intention and interest & Point of Adoption & Implementation & Confirmation & {$[10]$}
\end{tabular}

But considering adoption as a decision is not new: "innovation implementation presupposes innovation adoption, that is, a decision, typically made by senior organizational managers, that the employees within the organization will use the innovation in their work" [11]. This definition is also used in Information Technology Adoption literature for Technology Acceptance Models (TAM) : "TAM2 reflects the impacts of (...) forces impinging on an individual facing the opportunity to adopt or reject a new system" [12]. This is in continuity with Roger's model in which stage 3 can lead to adoption or rejection, and Stage 5 is the continued (or effective) adoption or rejection.

In BIM-specific literature, Succar and Kassem [13] describe BIM adoption as "a single construct combining the concepts of implementation and diffusion".

Given that we focus on the process through which companies go through to be able to use BIM, we must make a clear distinction between the decision to adopt (which we will call Decision of Adoption or DoA), when Implementation is effective (EI effective implementation), and the moment Technology has been effectively adopted (Confirmation of Adoption or CoA) (fig. 2 presented in part 4).

\section{BIM adoption influencing factors}

Innovation adoption is a long and complex process, of which implementation is a part. It is necessary to differentiate what influences decision to adopt BIM and what impacts the success of implementation. 


\subsection{Risk Management}

BIM literature has focused much on the level of adoption (especially comparative analysis) and benefits associated with implementation [5, 6, 14-16]. But any operation that generates benefits is also likely to produce negative effects [17]. Digital transition and change in a company is a risky operation.

Risk event is "what might happened to the detriment or in favor of the project" [17]. All risk events do not have the same chance to occur, this is called uncertainty of the even [17]. Risk management consists in identifying risks, analyzing them and formulate a response to anticipate their occurrence $[5,17,18]$. It is therefore interesting to consider risk management in BIM implementation methods.

Some research focus on risks on BIM projects [18], we focus on risks for firms. We aim to identify recurring risks (organization death, returning back to previous practices, and so on.) and risk factors (what increases the likelihood that the risk occurs) related to digital transition in design firms.

Bonanomi [5] identified two types of risk factors for implementation : endogenous (coming from internal context of the firm) and exogenous (coming from external context of the firm) risks. Social, managerial, technical, economical and institutional risks linked to BIM implementation in design firms are identified in the literature $[5,18]$. We propose to link these risk factors with generic literature on innovation adoption and change management in order to clearly differentiate adoption decision factors and implementation factors.

\subsection{Innovation adoption factors}

Research on the factors that influence decision to adopt is numerous, and arise from various fields.

Sociological psychology has been investigated to understand psychological, social aspects involved in decision of adoption of an innovation: these models and theories mainly focus on the perception a user has on the technology that determine the ease of use and usefulness of this technology. This perception is itself partially determined by the user profile and characteristics. The best known of these theories one is Technology Acceptance Model (TAM), proposed by Davis [19] and updated with Venkatesh [12]. A representative state of the art of these models can be found in Tetard and Collan's work [20].

Economy, sociology and strategic management have been investigated through Institutional Theory (INT) [21], which describes the institutional pressures that motivate organizations to perform change : coercive (responding to cultural expectations), mimetic (facing uncertainty), normative (undergoing standardization of training and procedures).

A summary of factors that affect innovation adoption coming from various literature can be found in [22] (innovation-specific), cited by [10] (BIM-specific) :

\section{- Perceived BIM/innovation characteristics:}

Firm's idea about value of the innovation [22] as perceived usefulness of a technology and perceived ease of use [19], relative advantage, compatibility, complexity, triability, observability, and technological factors [8].

- Adopter characteristics: (this factor does appears in [22], and is integrated to "internal environment" in [10]) Company's general attitude towards the type of innovation, and financial resources it devotes to IT technologies.

- Internal environment characteristics:

Top management support, communication behavior, financial resources, organizational readiness, social motivations, organization culture, willingness/intention, organization size.

- External environment characteristics:

Coercive pressures, mimetic pressures, normative pressures, market forces and supply chain integration

This literature is very useful to understand what can make an enterprise or an individual choose to adopt a technology. Factors that facilitate decision of adoption are called adoption decision drivers. But the factors here identified intervene before the decision to adopt (at stage 3 in Roger's model). So it doesn't help understanding what sometimes lead adoption to fail after decision of adoption has been taken. 


\subsection{Are there companies unable to integrate an innovation/BIM?}

As we try to construct a method to facilitate digital transition in design firms, it is legitimate to ask whether certain companies could be unable to integrate BIM.

A large part of organizational, management and sociological literature subscribes to adaptation perspective [23]. In this perspective, leaders or top managers scan the environment of the organization to detect opportunities and threats and formulate strategic responses to adjust organizational structure appropriately. Changes are therefore made to lower organizational death rates of organizations.

The adaptation perspective has been challenged in 70's with population ecology theory [23-25] which argues that organizational have high levels of structural inertia which make organizational adaption difficult, and sometimes impossible. One of the major arguments of population ecology theory is that organizations rarely make major adaptive changes (organizational changes are considered more often disruptive - as does BIM) and that there are number of obvious limitations on the ability of organizations to adapt [24]. Two types of limitations are mentioned:

- Inertial pressure are the pressures that come from the company itself as 1- choices made previously (equipment and specialized personnel), 2- the kind of information decision makers receive, 3- internal political constraints, and 4- the history of the firm [24]. This implies that not all companies are equal in the face of change.

- External pressures are 5-legal and fiscal barriers, 6-information dissemination channels, 7-legitimacy constraints and $\mathbf{8}$-collective rationality problem [24].

Not all companies are equal in facing change, which is interesting in the perspective of massive BIM adoption, how BIM can be implemented, and consequences it can have on the AECO industry.

In Rogers' [8] and Ahmed's [10] models, only the rejection decision can stop the adoption process (at stage 3, see table 1). Hannan and Freeman describe pressures (internal / external) that can lead to implementation or reorganization fail, the different steps where implementation can stop and what form this failure can take (see fig. 1): an organization may die because it has not adapted quickly enough (d). If a structure decides to reorganize (a), the operation can lead to success (c), to death (e) or to a return to previous practices (b). It is also possible that the new configuration is not adapted to environment, and then the organization can die (f).

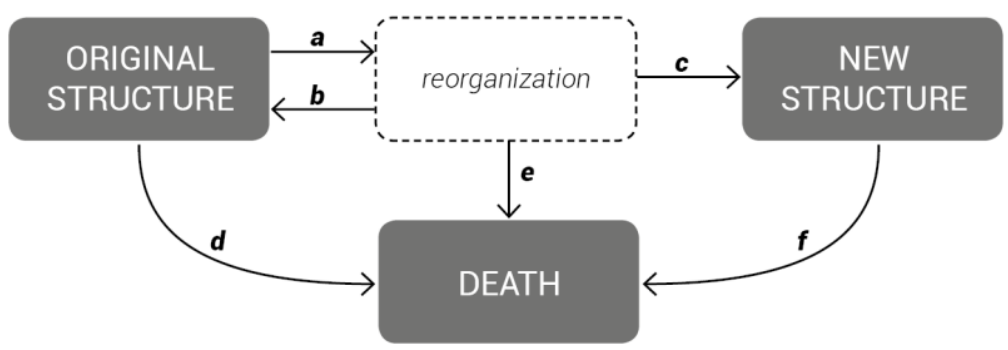

Figure 1 : State space for the Process of Fundamental Change in Organizational structure, adapted from [26].

In the population ecology theory, the term "population" refers to aggregates of organizations rather than member [24] : adaptation of organizational structure to environments occurs principally at the population level [26]. In view of that, organizations that fit the environment survive, and those who are not able to adapt quick enough die.

The way in which the identified factors influence firms' mortality has been the subject of hypotheses (called assumptions in [26]). They concern characteristics of the company (size, age specialized or generalist), external environment (stable, uncertain) and the implementation method for change (type, speed) [24]. Some of these hypotheses have been tested and empiric study of these factors do not show clear impact of these characteristics on mortality of an organization and have not shown predictive capacity of this theory [23]. These factors remain however interesting because they have not been investigated in the case of BIM adoption and implementation, and studying organizations as populations can help to identify general trends in BIM field. 


\subsection{Change management}

In the 80s and 90s, software development paradigm (when each company develops its own tools, adapted to its practice) gave way to software edition paradigm (publishers market software on a large scale for the greatest number). This changeover is at the origin of the very pragmatic managerial questions linked to the support of companies in the integration of information technologies [27]. Change management is a domain that provides theoretical/practical models and strategies to analyze and conduct change [3]. This discipline is focused on the implementation part of adoption, and can be really interesting to investigate BIM implementation.

On the basis of a change management state of the art [27], we summarized elements that are identified in this literature as factors that impact implementation. They are classified into two categories:

(1) the characteristics of the company context (table 2) and (2) change characteristics (table 3).

Table 2. Characteristic aspects of a company (1) at 3 different levels: the global level (L3), the organization level (L2) and the personal level (L1).

\begin{tabular}{clll} 
Level & Context & Description & References \\
\hline L3 & $\begin{array}{l}\text { External } \\
\text { context }\end{array}$ & Social, economic, competitive, and political environment. & {$[28],[4]$} \\
\hline L2 & Culture & Vision, principles, beliefs, values, projects (products), strategies & {$[29],[30],[28]$,} \\
& & & {$[31],[4]$} \\
\cline { 2 - 4 } & Interactions & Hierarchy, division of power, distribution of work and responsibilities, collaboration. & {$[29],[30],[28]$,} \\
& & & {$[31],[4]$} \\
\cline { 2 - 5 } & Systems & Software, hardware, processes & {$[29],[31],[4]$} \\
\hline L1 & People & People, experience, seniority, career stage, skills. & {$[29],[31]$}
\end{tabular}

Table 3. Change characteristics (2) that have been identified in the literature as playing a role in the success of the change (adapted from [27])

\begin{tabular}{|c|c|c|}
\hline Caract. & Dimension & Description \\
\hline \multirow[t]{2}{*}{ Extent } & Global & Change affects all activities and units of the organization. The company's strategy and culture evolve [27]. \\
\hline & Partial & $\begin{array}{l}\text { Change affects a portion of the organization, preserving the previous strategy, culture and structure. It is } \\
\text { most often insufficient to modify the company's performance [27]. }\end{array}$ \\
\hline \multirow[t]{2}{*}{ Depth } & Disruptive & $\begin{array}{l}\text { A disruptive change marks a big difference with past, with a clear discontinuity. It changes strategy, process } \\
\text { and organizational culture and affects the company's performance [26] [27]. }\end{array}$ \\
\hline & Adaptive & $\begin{array}{l}\text { An adaptive change is a modification of the actual situation. It makes evolve lightly content, process and } \\
\text { missions of the organization [26] [27]. }\end{array}$ \\
\hline \multirow[t]{2}{*}{ Rhythm } & Fast & $\begin{array}{l}\text { A fast change is a redress and a resolution against a past situation, but too rapid a change can put the } \\
\text { organization at risk [32]. }\end{array}$ \\
\hline & Slow & $\begin{array}{l}\text { It consists of a gradual approach to ensure a new balance thereafter. Too slow a change can lead to getting } \\
\text { used to an undesirable situation [32]. }\end{array}$ \\
\hline \multirow[t]{2}{*}{ Base } & Imposed & $\begin{array}{l}\text { Imposed change is a change for which management acts decisively and where there is little opportunity for } \\
\text { negotiation [27]. }\end{array}$ \\
\hline & Negotiated & $\begin{array}{l}\text { Managers are caught between limiting resistance to change and respond to customer demands. Convinced } \\
\text { that imposed change has little chance of success, they integrate teams to limit resistance. It is difficult to } \\
\text { place the cursor between firmness and negotiation [27]. }\end{array}$ \\
\hline
\end{tabular}

Elements in Table 2 are very similar to those found in the population ecology theory (inertial and external pressures). Factors summarized in table 3 have been the subject of empirical studies and action research: their involvement in success/failure of implementation have been demonstrated, but AEC-specific examples are rare. Lines [33] tried to determine what causes more resistance to change in the case of implementation of new processes in AEC firms (resistance to change can lead to adoption failure). He proposed hypothesis based on the organization characteristics (Project: scope, size, duration; People: position level, career stage) and change characteristics (Organizational expectations: implementation speed, organizational shift; implementation approach: change message received, presence of formal agents, involvement of change agent). He demonstrated that all these hypothesis, except « expected organization shift » are strongly correlated with resistance to change. BIM-specific studies of this type are extremely rare, and some of these factors are quite difficult to measure or to identify in firms. 


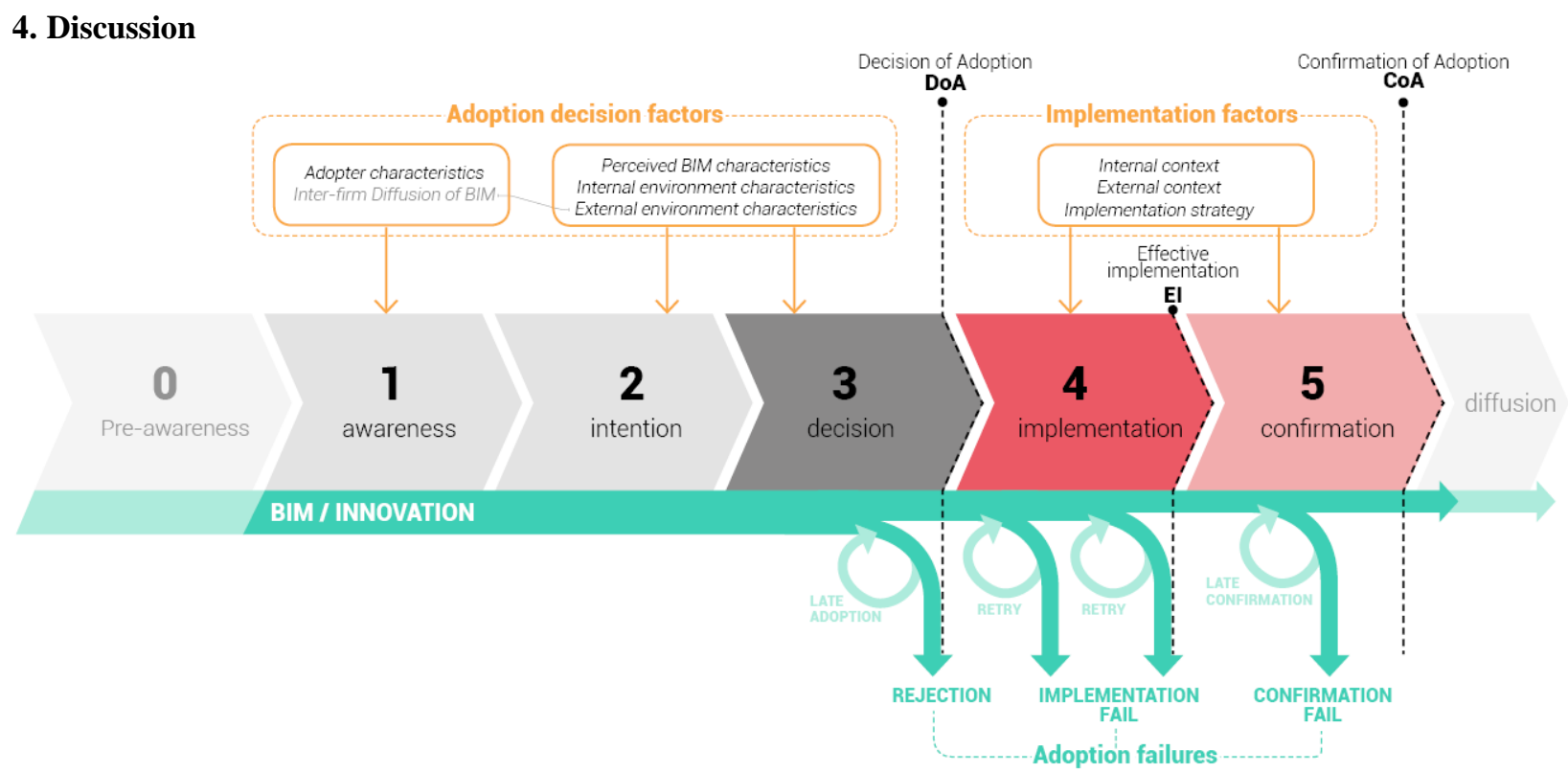

Figure 2 : Model of the BIM Adoption process, with possible adoption failures; adapted from [8, 10]

This figure is an evolution of the "conceptual model for investigating BIM adoption decisions" [10]. We do not use the term "conceptual model" to avoid confusion with "conceptual models" used in Information Systems to designate a representation of a system.

Innovation diffusion models and technology acceptance models have been progressively appropriated in BIMspecific literature. However, diffusion, adoption and implementation processes are insufficiently defined and described. Based on Roger's model [8, 10], we consider that BIM Adoption is a process (fig. 2), which begins with the awareness of the existence of this innovation (stage 1), followed-up by the eventuality of the intention (stage 2) and decision to adopt (stage 3). The Decision of Adoption (DoA) is an important moment, when the company's management begins to bring about $\mathrm{c}$ hange in the company; it also marks the beginning of the implementation process.

In the study of BIM adoption, the focus is often made on adoption decision factors (factors that influence decision of adoption). They can be summarized in four categories: perceived BIM characteristics, adopter characteristics, internal environment characteristics and external environment characteristics (including inter-firm diffusion of innovation).

Decision of a company's top management that the people in the firm will use BIM is not sufficient to make an organization adopt it or to explain the rate of BIM adoption in AEC industry. Some elements involved in the adoption process are beyond the control of the decision-making group and may cause the adoption to success or to fail, after the DoA. Implementation factors affect implementation (stage 4), under or beyond the control of the decision-making group.

Implementation factors have been explored in different fields and models, presented in this article. They can be classified into three categories, that do not carry the same name in the various literatures, but refer to the same concepts: internal context, external context and implementation strategy (table 4).

Table 4. implementation factors categories names in various literatures

\begin{tabular}{llll} 
& Internal context & External context & Implementation strategy \\
\hline Population ecology theory & Inertial pressure & External pressure & Nature or reorganization \\
\hline Risk management & Endogenous risk & Exogenous risk & Endogenous risk \\
\hline Change management & $\begin{array}{l}\text { Characteristic aspects } \\
\text { of a company }\end{array}$ & $\begin{array}{l}\text { Characteristic aspects } \\
\text { of a company }\end{array}$ & $\begin{array}{l}\text { Change characteristics } \\
\text { (table 3) }\end{array}$ \\
& $\begin{array}{l}\text { (L) \& 2 in table 2) } \\
\text { culture, interactions, } \\
\text { systems, people. }\end{array}$ & external context & \\
& & &
\end{tabular}


The adoption process can be interrupted (Adoption failures) after stage $\mathbf{3}$ at different steps:

- Stage 4: Adoption can fail at the beginning of implementation, for example if resistance to change is very strong in the company; it can also fail during implementation, if the company is not fast enough to operate change, if the company returns to previous practices or dies because of disruption created by change (fig 2).

- Stage 5: Adoption can fail after implementation, during the confirmation stage (fig 2), for example if the if the implemented technology is not effective in practice for the organization and is abandoned, or if the company dies or goes back to previous practices.

We have shown that the innovation adoption process can fail at many stages. Implementation factors are littleknown in the case of BIM, although recent research has taken a more in-depth look at this topic [34, 35]. We don't know yet what influences the more BIM adoption, despite the numerous surveys conducted on BIM topic [14, 36-39]. Some of the factors identified in this article can help understand what can lead implementation or adoption to fail. However, there is currently a lack of quantitative studies that focus on implementation factors. Of course, it would be difficult to set up an experimental protocol allowing a factor to be isolated in order to study its impacts.

\section{Conclusion}

Motivation to adopt an innovation changes with the number of other firms in industry that already successfully implemented this innovation. At the beginning of the inter-firm diffusion process, adopters are more focused on strategic importance of the innovation for the organization, and external forces like the parent company, industry competitiveness. Later, they tend to be focusing more around practical implementation issues and budget [22]. Given the increasing level of adoption of BIM and incentives for adoption provided by governments, it is important to focus now on very practical issues on the firm's implementation. Large-scale surveys that assess the level of BIM adoption are numerous, but seem to not focus on characteristics of the firms, and how they drive change.

It is important to note that the way change is taking place is little known while the stakes of massive BIM adoption are high. The review presented in this paper can be completed with the diffusion of a large-scale survey to architecture firms in order to fix the lack of information available on implementation factors in design firms. This research will be used to develop a method to support the implementation and digital transition of architecture firms in France.

This review also opens up other perspectives: it can be used to study the impact of massive BIM adoption in AECO industry, considering some companies may be unable to integrate these technologies. It is conceivable that the market will be restructured in a rather profound way, especially in France, where most of the companies are very small and still work in a very artisanal way.

\section{References}

[1] SUCCAR, Bilal. Building information modelling framework: A research and delivery foundation for industry stakeholders. Automation in Construction. 1 May 2009. Vol. 18, no. 3, p. 357-375. DOI 10.1016/j.autcon.2008.10.003.

[2] KASSEM, Mohamad, SUCCAR, Bilal and DAWOOD, Nashwan. Building information modeling: analyzing noteworthy publications of eight countries using a knowledge content taxonomy. In : [online]. American Society of Civil Engineers, 2015. [Accessed 24 August 2017]. Available from: http://tees.openrepository.com/tees/handle/10149/593102

[3] HOLZER, Dominik. The BIM Manager's Handbook, Part 2: Change Management. John Wiley \& Sons, 2015.

[4] PETTIGREW, Andrew M. Context and action in the transformation of the firm. Journal of management studies. 1987. Vol. 24, no. 6, p. 649670.

[5] BONANOMI, Marcella, PAGANIN, Giancarlo and TALAMO, Cinzia. BIM implementation in Design firms. Risk-response strategies to support change management. In : 41st IAHS WORLD CONGRESS. Sustainability and Innovation for the Future. 13 September 2016. p. 1-9.

[6] KASSEM, Mohamad and SUCCAR, Bilal. Macro BIM adoption: Comparative market analysis. Automation in Construction. 2017.

[7] STONEMAN, Paul and DIEDEREN, Paul. Technology diffusion and public policy. The Economic Journal. 1994. Vol. 104, no. 425, p. 918930.

[8] ROGERS, Everett M. Diffusion of innovations. Simon and Schuster, 1962.

[9] KARLSSON, Charlie. Innovation adoption and the product life cycle. PhD Thesis. Umela a universitet, 1988.

[10] AHMED, Ahmed, PAUL KAWALEK, John and KASSEM, Mohamad. A Conceptual Model for Investigating BIM Adoption by Organisations. In : . 4 July 2017.

[11] KLEIN, Katherine J. and SORRA, Joann Speer. The challenge of innovation implementation. Academy of management review. 1996. Vol. 21, no. 4, p. $1055-1080$. 
[12] VENKATESH, Viswanath and DAVIS, Fred D. A theoretical extension of the technology acceptance model: Four longitudinal field studies. Management science. 2000. Vol. 46, no. 2, p. 186-204.

[13] SUCCAR, Bilal and KASSEM, Mohamad. Macro-BIM adoption: Conceptual structures. Automation in Construction. 1 September 2015. Vol. 57, p. 64-79. DOI 10.1016/j.autcon.2015.04.018.

[14] MCGRAW HILL CONSTRUCTION. The Business Value of BIM for Construction in Major Global Markets: How contractors around the world are driving innovations with Building Information Modelling. Smart MarketReport. 2014.

[15] ARAYICI, Y., COATES, P., KOSKELA, Lauri, KAGIOGLOU, Mike, USHER, C. and O'REILLY, K. Technology adoption in the BIM implementation for lean architectural practice. Automation in Construction. 2011. Vol. 20, no. 2, p. 189-195.

[16] SMITH, Peter. BIM Implementation - Global Strategies. Procedia Engineering. 1 January 2014. Vol. 85, p. 482-492. DOI 10.1016/j.proeng.2014.10.575.

[17] AL-BAHAR, Jamal F. and CRANDALL, Keith C. Systematic risk management approach for construction projects. Journal of Construction Engineering and Management. 1990. Vol. 116, no. 3, p. 533-546.

[18] CHIEN, Kuo-Feng, WU, Zong-Han and HUANG, Shyh-Chang. Identifying and assessing critical risk factors for BIM projects: Empirical study. Automation in Construction. 2014. Vol. 45, p. 1-15.

[19] DAVIS, Fred D. Perceived Usefulness, Perceived Ease of Use, and User Acceptance of Information Technology. MIS Quarterly. 1989. Vol. 13, no. 3, p. 319-340. DOI 10.2307/249008.

[20] TÉTARD, Franck and COLLAN, Mikael. Lazy user theory: A dynamic model to understand user selection of products and services. In : System Sciences, 2009. HICSS'09. 42nd Hawaii International Conference on. IEEE, 2009. p. 1-9.

[21] DIMAGGIO, Paul J. and POWELL, Walter W. The iron cage revisited institutional isomorphism and collective rationality in organizational fields. In : Economics Meets Sociology in Strategic Management. Emerald Group Publishing Limited, 2000. p. 143-166.

[22] WAARTS, Eric, VAN EVERDINGEN, Yvonne M. and VAN HILLEGERSBERG, Jos. The dynamics of factors affecting the adoption of innovations. Journal of Product Innovation Management. 1 November 2002. Vol. 19, no. 6, p. 412-423. DOI 10.1016/S0737-6782(02)001753.

[23] SINGH, Jitendra V., HOUSE, Robert J. and TUCKER, David J. Organizational change and organizational mortality. Administrative science quarterly. 1986. P. 587-611.

[24] HANNAN, Michael T. and FREEMAN, John. The population ecology of organizations. American journal of sociology. 1977. Vol. 82, no. 5, p. 929-964.

[25] ALDRICH, Howard. Organizations and environments. Stanford University Press, 2008.

[26] HANNAN, Michael T. and FREEMAN, John. Structural inertia and organizational change. American sociological review. 1984. P. $149-164$.

[27] AUTISSIER, David, VANDANGEON-DERUMEZ, Isabelle and VAS, Alain. Conduite du changement, concepts clés: 50 ans de pratiques issues des travaux des auteurs fondateurs. Paris : Dunod, 2014. ISBN 978-2-10-070574-0.

[28] GREENWOOD, Royston and HININGS, Christopher Robin. Organizational design types, tracks and the dynamics of strategic change. Organization studies. 1988. Vol. 9, no. 3, p. 293-316.

[29] SAINSAULIEU, Renaud and SEGRESTIN, Denis. Vers une théorie sociologique de l'entreprise. Sociologie du Travail. 1986. Vol. 28, no. 3 , p. 335-352.

[30] BURGELMAN, Robert A. and MITTMAN, Brian S. An Intraorganizational Ecological Perspective on Managerial Risk Behavior. Evolutionary dynamics of organizations. 1994. P. 53.

[31] MINTZBERG, Henry and WESTLEY, Frances. Cycles of organizational change. Strategic management journal. 1992. Vol. 13, no. S2, p. 3959.

[32] KOTTER, John P. and COHEN, Dan S. The heart of change: Real-life stories of how people change their organizations. Harvard Business Press, 2002.

[33] LINES, Brian C., SULLIVAN, Kenneth T., SMITHWICK, Jake B. and MISCHUNG, Josh. Overcoming resistance to change in engineering and construction: Change management factors for owner organizations. International Journal of Project Management. 1 July 2015. Vol. 33, no. 5, p. 1170-1179. DOI 10.1016/j.ijproman.2015.01.008.

[34] HONG, Ying, SEPASGOZAR, Samad ME, AHMADIAN, A. F. F. and AKBARNEZHAD, Ali. Factors influencing BIM adoption in small and medium sized construction organizations. In : ISARC. Proceedings of the International Symposium on Automation and Robotics in Construction. Vilnius Gediminas Technical University, Department of Construction Economics \& Property, 2016. p. 1.

[35] MURGUIA SANCHEZ, Danny E., DEMIAN, Peter and SOETANTO, Robby. A systemic BIM innovation model in the construction supply chain. . 2017.

[36] NBS, MALLESON, A., KATO, H., POPÍŠILOVÁ, B., WATSON, D. and FRIBORG, G. NBS International BIM Report 2016.2016.

[37] NBS, WATERHOUSE, Richard, PARKINSON, Kieran and MALLESON, Adrian. National BIM Report 2017. . 2017.

[38] MCGRAW HILL CONSTRUCTION. The business value of BIM in Europe: Getting building information modelling to the bottom line the united kingdom, France and Germany. Smart Market Report. 2010.

[39] BATIACTU and PTNB. Baromètre - Le BIM dans le secteur du BTP [online]. 2017. Available from: http://www.batimentnumerique.fr/uploads/DOC/PTNB\%20-\%20Barometre\%202\%20-\%20Mars\%202017\%20-\%20Rapport\%20detaille.pdf 